\title{
Embryo as a Patient: New Era Opened
}

\author{
Jan Tesarik ${ }^{1,2 *}$ and Carmen Mendoza ${ }^{1,2}$ \\ ${ }^{1}$ MARGen Clinic, Granada, Spain \\ ${ }^{2}$ MARGen Mendoza-Tesarik Foundation, Granada, Spain
}

Submission: November 18, 2017 ; Published: December 13, 2017

*Corresponding author: Jan Tesarik, MARGen Clinic, Camino de Ronda 2, 18006 Granada, Spain, Email: jtesarik@clinicamargen.com

\begin{abstract}
Since the first successful in vitro fertilization treatment, 40 years ago, preimplantation embryos can be visualized and examined in the laboratory before being transferred into the patient's uterus. This oportunity has been widely used to select the most viable embryos to be transferred. Different criteria were employed to carry out this selection. Since 1990, preimplantation genetic diagnosis has been included to achieve this goal. Embryos diagnosed as normal were transferred, while those deemed abnormal or uncertain were destroyed. According to this practice, many couples with no normal embryo available could not receive the treatment desired. The recent progress in cell manipulation, together with the current knowledge in the field of molecular genetics, has opened a new era, marked by the possibility of curing genetically abnormal embryos, converting them into normal ones and transfering them to the mother to achieve pregnancy and birth.
\end{abstract}

Keywords: Preimplantation genetic diagnosis; Preimplantation genetic screening; Next-generation sequencing; Mitochondrial DNA disease; CRISPR-Cas system; Gene editing technology; Embryo gene correction; Age-related aneuploidy; Down syndrome

\section{History}

The first successful in vitro fertilization (IVF) attempt was carried out 40 years ago [1]. Since then, it has been posible to evaluate early human embryos before being transferred into the mother's uterine cavity. This policy was at the origin of different embryo-selection methods, used to transfer some embryos from the available cohort and to discard others, according to different kinds of criteria. Since 1990, when the first preimplantation genetic diagnosis (PGD) was reported [2], genetic criteria have been gaining weight, culminating in the recent technologies of whole-genome analysis by preimplantation genetic screening (PGS) using next-generation sequencing (NGS) [3]. This kind of analysis can now be done in a completely non-invasive way, without the need for embryo biopsy, by sequencing soluble DNA released by the embryo to the culture medium [4]. Regardless the technique chosen, the genetic analysis of preimplantation embryos is traditionally aimed at the selection of presumably normal embryos to be transferred to the uterus, while the other embryos (with an abnormal or inconclusive test result) are discarded.This all-or-none approach to embryo selection can lead to the impossibility of performing embryo transfer, when none of the embryos available is diagnosed as normal.

This situation has changed dramatically over the past few years, when sufficient experience in cell manipulation and molecular biology techniques has accumulated to allow abnormal embryos to be rescued rather than discarded. This trend first appeared in the late nineties, when nuclear transfer techniques were developed to obtain normal embryos for women with severe abnormalities of oocyte cytoplasmic components [5].
One year ago, this technique has been applied with success to prevent the transmission to progeny of a rare mitochondrial DNA disease, Leigh syndrome [6]. Fourty years after the first successful IVF, this achievement is of highly symbolical value, marking the beginning of a new era in which the embryo is going to be considered as a patient instead of a mere instrument of reproduction.

\section{Present}

In the last two years, several technological innovations with potential application in the correction of genetically abnormal preimplantation embryos have been reported. Most of them use the system called CRISPR (Clustered Regularly Interspaced Short Palindromic Repeats). The CRISPR system, coupled with Cas genes, coding for nucleases capable of cutting the DNA sequence, is the principle immune system acting agains viruses in prokaryotes (bacteria and archaea) $[7,8]$. If a prokaryote cell is attacked by a virus, the CRISPR/Cas system can incorporate viral DNA sequences and efficiently detect and destroy DNA from further atacks by similar viruses. In 2013 it was discovered that RNA-guided Cas9 nucleases derived from CRISPR-Cas systems make it posible to cut and paste parts of genomes of diverse organisms [9] and, since then, modified CRISPR/Cas systems have been tested as tools for gene editing in eukaryotic cells.

The technique of gene editing with the use of the CRIPR/ Cas technology has been first applied to human preimplantation embryos in 2015 [10]. The technique was initially tested on abnormally fertilized (tripronuclear) human zygotes to try and 
cleave the endogenous $\beta$-globin gene. Even though the goal was achieved in some cases, the efficiency was relatively low, and there were many side effects, some of them leading to embryo mosaicism [10]. In the year 2017, the technique was applied to normally fertilized (dual pronuclear) human zygotes donated for research, with similar limitations [11].

Modifications of the CRISPR/Cas-based gene editing technique, enabling a higher precision on the edited genes and limiting undesirable side-effects, have been reported later in 2017 [12,13]. Even though, by precaution, no genetically corrected embryo has been transferred to the mother's uterus yet, these findings show the way how clinically efficient and safe protocols can be designed in the future.

\section{Future}

The perspective of the development, in the near future, of efficient and safe laboratory protocols for gene editing in human embryos is challenging the way preimplantation embryos are dealt with nowadays. At present, preimplanation genetic diagnosis and screening serve to distinguish presumably normal embryos from those affected by different genetic anomalies. The aim of these techniques is to use only the normal embryos, while the abnormal ones are discarded. In the relatively near future, it will be possible to procreate also with the originally abnormal embryos, by transferring them to the patient's uterus after appropriate correction. This will be of help especially in cases in which only few or no normal embryos are available. Moreover, the use of genetically corrected frozen embryos in subsequent cycles will avoid unnecessary repetions of the clinical and laboratory procedures which would be required for a new complete in vitro fertilization attempt. Consequently, embryos diagnosed with different genetic abnormalities at present can be cryopreserved and stored until an adequate laboratory technique for their correction is available.

The above strategy will also make reproduction more acceptable for certain genetic anomalies in which the incidence of transmission is high. For instance, half of the progeny of women affected by Down syndrome are likely to also be affected, whereas the other half have a normal karyotype [14]. It is now possible to look for trisomy 21 in these embryos, to transfer immediately embryos with normal karyotype and to keep the rest of the embryos frozen until they can be cured in the future. This strategy would also be applicable to other syndromes caused by chromosomal abnormalities and gene mutations as well as to spontaneous, age-related aneuploidies.

\section{Conclusion}

All abnormal embryos can now be considered as patients whose therapy will be possible in the relatively near future. Cryopreserving such embryos, rather than destroying them, will not only increase the chances of the patients to become parents without repeating the whole treatment cycle, but it will also relieve the psychological stress of the patients, caused by the destruction of part of their embryos.

\section{References}

1. Steptoe PC, Edwards RG (1978) Birth after the re reimplantation of a human embryo. Lancet 2(8085): 366.

2. Handyside AH, Kontogianni EH, Hardy K, Winston RM (1990) Pregnancies from biopsied human pre implantation embryos sexed by Y-specific DNA amplification. Nature 344(6268): 768-770.

3. Wells D (2014) Next-generation sequencing: the dawn of a new era for pre implantation genetic diagnostics. Fertil Steril 101(5): 1250-1251.

4. Xu J, Fang R, Chen L, Chen D, Xiao JP, et al. (2016) Non invasive chromosome screening of human embryos by genome sequencing of embryo culture medium for in vitro fertilization. Proc Natl Acad Sci USA 113(42): 11907-11912.

5. Tesarik J, Nagy ZP, Mendoza C, Greco E (2000) Chemically and mechanically induced membrane fusion: non-activating methods for nuclear transfer in mature human oocytes. Hum Reprod 15(5): 11491154

6. Zhang J, Liu H, Luo S, Lu Z, Chávez-Badiola A (2017) Live birth derived from oocyte spindle transfer to prevent mitochondrial disease. Reprod Biomed Online 34(4): 361-368.

7. Barrangou R, Fremaux C, Deveau H, Richards M, Boyaval P, et al. (2007) CRISPR provides acquired resistance against viruses in prokaryotes. Science 315 (5819): 1709-1712.

8. Horvath P, Barrangou R (2010) CRISPR/Cas, the immune system of bacteria and archea. Science 327 (5962): 167-170.

9. Mali P, Esvelt KM, Church GM (2013) Cas9 as a versatile tool for engineering biology. Nat Methods 10(10): 957-963.

10. Liang P, Xu Y, Zhang X, Ding C, Huang R, et al. (2015) CRISPR/Cas9mediated gene editing in human tripronuclear zygotes. Protein Cell 6(5): 363-372.

11. Tang L, Zeng Y, Du H, Gong M, Peng J, et al. (2017) CRISPR/Cas9mediated gene editing in human zygotes using Cas9 protein. Mol Genet Genomics 292(3): 525-533.

12. Li G, Liu Y, Zeng Y, Li J, Wang L, et al. (2017) Highly efficient and precise base editing in discarded human tripronuclear embryyos. Protein Cell 8(10): 776-779.

13. Ma H, Marti-Gutierrez N, Park SW, Wu J, Lee Y, et al. (2017) Correction of a pathogenic gene mutation in human embryos. Nature 548(7668): 413-419.

14. Bovicelli L, Orsini LF, Rizzo N (1982) Reproduction in Down syndrome. Obstet Gynecol 59(6 Suppl): 13S-17S. 
This work is licensed under Creative Commons Attribution 4.0 Licens

DOI: 10.19080/JGWH.2017.07.555720
Your next submission with Juniper Publishers will reach you the below assets

- Quality Editorial service

- Swift Peer Review

- Reprints availability

- E-prints Service

- Manuscript Podcast for convenient understanding

- Global attainment for your research

- Manuscript accessibility in different formats

( Pdf, E-pub, Full Text, Audio)

- Unceasing customer service

Track the below URL for one-step submission https://juniperpublishers.com/online-submission.php 